\title{
"Blackout!" Unpacking the Black Box of the Game Event
}

\section{Steven Conway \& Andrew Trevillian}

\section{ABSTRACT}

In this article we propose a new ontology for games, synthesising phenomenology, Latourian Actor-Network Theory and Goffmanian frame analysis. In doing so we offer a robust, minimal and practical model for the analyst and designer, that clearly illustrates the network of objects within the 'Black Box' of any game, illuminating how each object (from player to memory card to sunlight) may move between three levels of the Game Event: Social World, Operative World and Character World. Abbreviating these worlds, a shorthand for the model is SOC (Social/Operative/Character).

\section{Keywords}

Ontology, Frame Analysis, Actor-Network Theory, Object-Oriented Ontology

\section{INTRODUCTION}

"When many elements are made to act as one, this is what I will now call a black box.” (Latour 1988, p.131)

\section{Noisy Neighbour}

Playing FIFA 14 (EA Canada 2013) on my new Xbox One, I am engrossed. My team, SurReal Madrid, are struggling to make it beyond the middle of the English Premier League. Losing to West Ham United is not going to help matters. Suddenly a noisy neighbour outside my window interrupts, a particularly garrulous species of 
bird, either cheering my team on or booing from the sidelines; it's hard to know. Momentarily, my conscious experience moves from the game to the window, and I peer out to get a better view of my beaky assailant.

I cannot make the bird out amongst the bushes, and return to my game. It takes a few seconds but I manage to once again reorient my focus towards the game world, belief in my team as more than an arrangement of pixels on my television returns. I lose the match as the bird becomes louder than before; his orientation becomes clear another fussy, over-entitled fan booing his team off the pitch.

The loading screen fades, replaced by an email from my chairman, admonishing me-as-manager for swearing on the sidelines during the match. I am baffled, and, as ever, turn to Google for answers. It turns out that the Kinect 2.0, packaged with the Xbox One, tracks environmental noise during FIFA 14. If the user is heard to swear by the Kinect, he or she will receive such an email.

Yet no such swearing occurred. Indeed, my only contribution was a mournful silence throughout the match. Then it dawns on me: that bloody bird has cost me a slap on the wrist from the board. The Kinect had, all by itself, moved the bird from the world of nature straight into the game world, not so much as even notifying me of the intrusion.

How am I to comprehend such a moment? Metalepsis? Paratextual? Non-diegetic? Did the machine do this? The operator? The bird? Is it real? Virtual? Both?

\section{Capturing The Game Event}

The narratological concept of metalepsis is not a satisfactory description, as the bird's intrusion is an unexpected consequence of the Kinect's sensitivity, certainly not intended by the author as an aesthetic strategy; similarly it is not paratextual in any official capacity, and if categorized as such would broaden the definition of the term so far as to render it meaningless. The bird is non-diegetic, for sure, but not in the same way that a floating health box is non- 
diegetic, or a soundtrack: it is not a designed non-diegetic, but instead some egregious, anomalous invader. It is also neither operator nor machine, and therefore Galloway's 'four moments' model (2006) breaks down in this instance.

If we hoped to map out such a relation (bird to Kinect) for design purposes, Schell's (2010) elemental tetrad finds no space for a cheeky fowl; Hunicke et al's MDA (Mechanics, Dynamics, Aesthetics) (2004) framework, ultimately concerned with the intended designerplayer relationship, may designate environmental sensitivity via the Kinect as part of the mechanics, but offers little insight in regards to the bird's existence: beginning with the assumption that a game is a dialog between designer and player, the model is understandably silent on the question of squawking animals.

Taking his cue from Haraway's concept of the cyborg, Latour's accounting for the non-human, and Deleuze's articulation of ethology, Seth Giddings ponders the moment of play, the 'Game Event' as we will discuss, in his article Events and Collusions: A Glossary for the Microethnography of Video Game Play:

"The event is constituted by the coming together in play, the collusion of material and imaginary elements: the operations of games (their conventions, rules, and prescriptions), embodied knowledge and technicities (and pleasures, anxieties, frustrations, imagination), play practices (role play, toy play), screen media images and characters, virtual game worlds (and their physics, automata, and affordances), and all sorts of bodies.” (2009, p.156)

Keogh (2014) ruminates upon similar issues in regards to games criticism, whilst Apperley and Jayemanne (2012) have recently called attention to a long-overdue turn towards the material in Game Studies. We align ourselves with this trajectory, and hope to move the argument forward through introduction of a model that facilitates the mapping of these heterogenous parts, and their relationships with one another, as generative of the Game Event. 


\section{GENESIS OF OUR MODEL}

\section{Theoretical Influences}

In devising our model we have drawn primarily upon the sociology of Erving Goffman (1972; 1973; 1986), various aspects of phenomenological work (Ash 2013; Clark 2003; Dourish 2004; Heidegger 2008), and the phenomenological sociology of Alfred Schutz ([1945] 1962), particularly his focus upon the generation of intersubjective meaning. Relatedly, the concept of affordance, as developed through the ecological psychology of James J. Gibson and its adaptation by Donald A. Norman (2002), is brought into our understanding of this meaning-making process. We also incorporate Actor-Network Theory (ANT) (Latour 1988; 1993; 2005) and the Object-Oriented Ontology (OOO) of Graham Harman (2011) as a means of extending meaning-making labour to the variety of nonhuman actors present within the Game Event; indeed, Harman's OOO may be productively understood as the combination and modification of Latour and Heidegger's worldviews.

One of Harman's most original contributions thus far has been to reinscribe Latour's ANT with essence: Being precedes relationality. Briefly, an object is never fully exhausted through its relations to other objects: my access to an apple is different to the way fire, a knife or a worm access it. Yet no entity has privileged access to the real object (as opposed to sensual object): none can touch its essence. Instead the apple object is accessed indirectly, through each relating object's specific affordances.

Our model follows Harman: no object in the Game Event is fully exhausted by its relation to any other object. Each object in the network always holds something in reserve and is therefore able to transform the situation. While some objects may have particular meanings at particular moments for other objects, this is always open to change.

Phenomenology

Phenomenology can be briefly summarised as the philosophy of 
human experience. A central concept we borrow from phenomenology is 'intentionality': this describes the way in which cognition is directed towards a world, its objects and events. Subscribing to the hermeneutic phenomenology of Martin Heidegger (2008), expanded upon by Gadamer (1976) and Ricoeur (1981) amongst others, we understand any object's relation to another as, fundamentally, an act of interpretation, inseparable (indeed reliant upon) each object's capacities (i.e. affordances) and context. Following this, we also leverage for our model an understanding of experience that collapses any Cartesian dualism. As Dourish summarises:

"The nature of being - how we exist in the world - shapes the way that we understand the world, because our understanding of the world is essentially an understanding of how we are in it. So Heidegger rejected the dualism of mind and body altogether. He argued that thinking and being are fundamentally intertwined.” (2004, p.107)

Heidegger's term for the human being, Dasein, 'being-there' (often summarised as being-in-the-world), emphasises the embodied, situated nature of cognition. Building on this, Heidegger offers two primary modes of interaction with equipment (defined as tools oriented towards a particular end): zuhandenheit (ready-to-hand) and vorhandenheit (present-at-hand). When, due to my competence at being-there, I act through an object that withdraws from conscious circumspection, yet mediates my action, it is zuhanden. Yet if the object fills my intentionality, it is vorhanden. For example in typing a sentence the keyboard is zuhanden; I am not aware of each individual keystroke as I type, my fingers have a proprioceptive intelligence and locate the appropriate keys without conscious effort. Yet in writing this sentence a key jams; the keyboard is now unready-to-hand and I am beset by aporia. The object appears now slightly alien to me and I begin thinking on each keystroke as I ponder the jammed key's material and shape: it becomes vorhanden. 


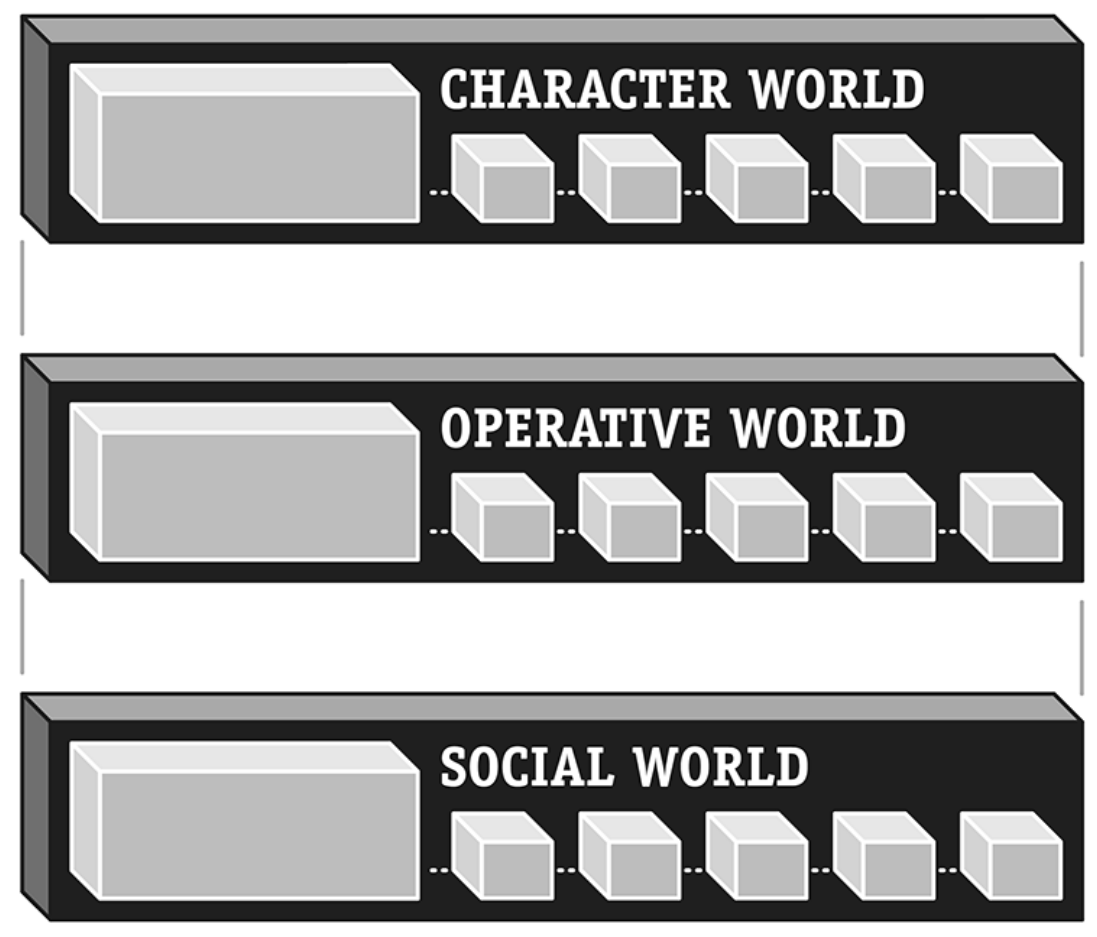

Figure 1: Three levels of the Game Event: the Social World, the Operative World and the Character World.

Crucial to our model is the way in which the object's hermeneutic orientation changes between three levels of the Game Event: the Social World, the Operative World, and the Character World (see Figure 1). For example the human player, as Dasein, maintains the capability to switch levels moment to moment, literally between milliseconds in some instances, such as playing in a crowded street on a mobile phone: immersed in the Character World I tap my thumb against the screen to make a dialog choice, I switch to Social World and check the street name, then to Operative World and check the score, and so on. This all may happen in the space of a second or two.

One must always exist in the Social World for a Game Event to take 
place: obviously I must be in an environment that already affords console gaming before I can play FIFA 14. Therefore FIFA 14 is the confluence of many objects, often invisible to the analyst: from the macro-scale objects (for example electricity, broadband infrastructure and government policy) to the micro (a television of appropriate specification, console apparatus, furniture). Therefore if one's intentionality is oriented towards the Character World (the world where object relations take on symbolic meaning, allowing us to speak of 'shooting' and 'jumping' in digital games as opposed to 'pressing the right trigger' or 'pressing the A button') then we take for granted that the player always-already inhabits the Operative and Social World; it is simply that these worlds have withdrawn from my direct attention, for the moment, in a zuhanden manner.

Informing our articulation of these worlds is Alfred Schutz' ([1945] 1962) work that expanded upon Husserl's initial notion of the 'lifeworld' (lebenswelt): that orientation towards a realm of being in which a 'natural' attitude can be taken, in which we assume a constancy of meaning and structure. Schutz' expansion was concerned with the generation of intersubjective meaning, how this structure and meaning ossifies into a common life-world shared between people through the invention and sharing of interpersonal symbols. Fundamental to this is Schutz' assertion that the life-world is a space of embodied action and interaction, "our bodily movements - kinesthetic, locomotive, operative - gear, so to speak, into the world, modifying or changing its objects and their mutual relationships” (Schutz [1945] 1962, p.209). Across time, Schutz believed multiple realities are formed, different worlds of structure and meaning that branch from the initial life-world, or as Goffman might say, primary frameworks that feed into secondary ones. Schutz was also, to our knowledge, one of the first phenomenologists to recognise the autonomy of objects, the non-human within the lifeworld, and to accord to them a degree of agency, which as mentioned is a metaphysical premise of our model.

Frame Analysis and Object-Oriented Ontology

Erving Goffman was an habitual taxonomer of the social. Through his system of 'frame analysis' (1986), Goffman was interested in 
explaining how we understand social reality, i.e. what we regard as authentic in a particular situation, and how we attune our performance to suit. When we talk of the 'everyday', Goffman would explain this as shorthand for our experience with a 'primary framework' (1986, p.21), a macro framework instantiated by society at large: workplaces, malls, cafes, supermarkets, roads. Secondary frames are 'transformations' (1986, p.156), described well by Deterding as "instances where a strip of experience that is organised and intelligible in terms of a primary framework is transformed modelled on the primary one but altered systematically in terms of the 'second' frame” (2013, p.62). There are two modes of transformation: 'fabrication', where one or more participants attempt to convey a false understanding of the situation, e.g. con artists, pranksters etc., and 'keys', "the set of conventions by which a given activity, one already meaningful in terms of some primary framework, is transformed into something patterned on this activity but seen by the participants to be something quite else” (Goffman 1986, p.43-4). Again, Deterding summarises eloquently that "keys are intentionally equilibrial transformations - all participants are supposed to be jointly aware of and upholding the transformation - whereas fabrications are intentionally disequilibrial ones" (2013, p.62, emphasis in original).

Keys then, are essential to play: what could be construed as unlawful assault can be rekeyed as boxing; running may be rekeyed as a race; moving tokens on a board may be rekeyed as Chess. But crucially, rekeying is only valid if the transformation of the situation is mutually accepted by all present, human and non-human. For example the affordances of a heavy wooden table resolutely resist my attempts to rekey it as a soccerball. Our model is therefore concerned with keys, rather than fabrications: though the latter is of interest, we locate it on the margins of play, associated with triflers, spoilsports and cheats. We hold that any fabrication is likely, at some point, to result in the Game Event prematurely breaking down.

Epistemologically, then, Goffman advocated a constructivist view of reality, an intersubjective process of meaning creation. In this 
manner one's 'reality' has an inherently unstable character, since the environment can undergo resignification at any moment, as does the 'self', since the performance required of a person may also demand alteration to suit a new situation:

"Starting with the traditional notion of the individual as selfidentified with the figure he cuts during ordinary interaction, I have argued some frame-relevant grounds for loosening the bond: that playfulness and other keyings may be involved which sharply reduce personal responsibility; that often what the individual presents is not himself but a story containing a protagonist who may happen also to be himself; that the individual's presumably inward state can be shared around selectively, much as a stage performer manages to externalize the inner feelings of the character he enacts.” (1986, p. 541).

Following Graham Harman’s (2011) Object-Oriented Ontology and its fusion of Latourian and Heideggerian principles, we propose to extend this mutability of identity to all object-relations, not just the human. This is not simply to advocate a sociomaterial perspective, that the meaning of an artefact only comes into being when enacted by the human or society at large. Instead, as per Harman's OOO, we argue that the meaning generated by an object's relationship to the human is just one example of many interpretations generated through different object relations: the DualShock 4 controller has a different relationship to the human player than it does to the PlayStation 4, electricity and Infamous Second Son (Sucker Punch Productions 2014).

Also, we hold that changes in one object relationship have demonstrable effects upon the network. For example when playing Infamous Second Son one possible activity is graffitiing public space: spray-painting various walls, roofs and monuments within the game world. In those moments, the game gestures for you to switch your grasp of the DualShock controller, to hold it as a spraycan; the DualShock's LED changes to match the colour of paint. This 
modification of the Infamous Second Son-DualShock relationship attempts, in turn, to rekey (or as we will come to, upkey) the humanDualShock relationship. If I accept this attempt, I may now perceive my controller not as zuhanden (ready-to-hand), a cyborgian extension of my body within the Operative World, but instead as this strange vorhanden (present-at-hand) phenomenon within the Character World, the DualShock-as-spraycan, demanding new modes of perception, both ocular and tactile, in a novel, but momentarily jarring way for the player.

Though Goffman was clearly aware of certain impacts the non-human may have upon the frame, there is little doubt his discussion maintains a sociomaterial accent. For example, "I argue that the meaning of an object (or act) is a product of social definition... The meaning of an object, no doubt, is generated through its use” (Goffman 1986, p.39). Our model sees little value in asymmetrical dichotomies and flattens these relations: yes the human interprets the meaning of the object, but vice-versa the object supports definition of the human. A human cannot be a driver without a car, or a swimmer without water. Again Deterding offers insight:

"[A]ctors and environments always find themselves in a moving equilibrium of relative alignment or misalignment... on the one hand, framing is a process continually open to contestation and change, including actors' active reconfiguration of objects and settings to suit a (re)framing... settings and objects partake in the institutionalisation of frames, and specific settings and objects suggest, support, resist specific framings.” (2013, p.119)

Correspondences between sociomaterialism and Latour's ActorNetwork Theory (ANT) are clear; Latour simply takes this relational ontology to its only coherent metaphysical conclusion. In We Have Never Been Modern, Latour describes actors (by which he means both human and non-human) as "endowed with the capacity to translate what they transport, to redefine it, redeploy it, and also to betray it" 
(1993, 81). Though following Latour in ascribing agency to the nonhuman, we once more follow Object-Oriented Ontology (OOO) in using the term 'object' instead of 'actor/actant' both to avoid any anthropomorphic connotation, and to stress the ontological (but not epistemological) status of objects, as Levi Bryant offers:

"[T]here is only one type of being: objects. As a consequence, humans are not excluded, but are rather objects among the various types of objects that exist or populate the world, each with their own specific powers and capacities.” (Bryant 2011, p.20, emphasis added)

Therefore we are not advocating a radical reductionism, as if we should compare humans directly to Chess pawns, mobile phone apps and Deadpool. Instead, we proceed from the premise that, prior to analysis, we cannot assume a hierarchy with the human at the apex. For instance when playing football, rain, wind and potholes often defeat my body; indeed severe enough rain or wind breaks the Game Event entirely. As Ian Bogost offers, "many people misconstrue object-oriented ontology as a singular material affair, as a reductionism: “everything's an object." But instead, proponents of OOO hold that all things equally exist, yet they do not exist equally" (2010, online, emphasis in original).

\section{Adaptation}

Following feedback, we have simplified and adapted aspects of the ontological and epistemological paradigms drawn upon to enhance clarity and diagnostic capability. In particular we have radicalised Goffman's concept of keying, influenced primarily by Fine’s (1983) Deterding's (2013) and Linderoth's (2012) application of these terms in discussing tabletop and digital games. Though aware that 'upkeying' and 'downkeying' were invoked by Goffman to describe only accidents, miskeyings of frames, we follow Linderoth (ibid.) in adapting upkeying and downkeying as fruitful orientational metaphors describing one's disposition within a frame: the more one upkeys, the more one commits to the role within the Game Event; the more one downkeys, the more one assumes disinterest in the 
focused encounter (detailed in Section 3a), for example withdrawing as Character Player but remaining as Social Actor.

We do, however, intend to have our cake and eat it too. That is to say, we do still take on board part of Goffman's meaning, in that the upkeying or downkeying initiated by an object is always a dangerous manoeuvre, always at risk of being rejected by other objects to which it relates. This is due to the tension inherent to any frame, the network of objects that comes together momentarily to define the situation, as Goffman expands:

"[T]ension here refers... to a sensed discrepancy between the world that spontaneously becomes real to the individual, or to the one he is able to accept as the current reality, and the one in which he is obliged to dwell... the coherence and persistence of a focused gathering depends on maintaining a boundary, so the integrity of this barrier seems to depend upon the management of tension.” (1972, p. 40)

If we extend this management of tension to the non-human actor, it is clear to see how it too may provoke rekeying, or break the Game Event entirely. Examples abound: glitches within a digital game may undertake the labor of keying, as the user negotiates a new definition of the situation; haptic feedback upkeys my hands (or other parts of my body) as metonym for my avatar's physical or emotional experiencing of the Character World, my hands becoming hands-asbody, or hands-as-temperament; the football punctures and the frame is broken, downkeying all connected objects back to the Social World.

In summary, we hold that all objects, human included, may maintain a certain disposition: an orientation towards the Game Event. Sometimes this disposition is mandated by human intentionality in the moment of play, other times we argue it is clear this disposition is intended by the designer; due to the nature of interpretation we can only ever establish this position through doxa. For example, it is popular opinion that Hideo Kojima, creator of the Metal Gear Solid (Konami Computer Entertainment Japan 1998-present) series, 
reorients the disposition of much console apparatus so that it appears within the Game World, or as we will discuss in section 4, upkeys objects from Social to Character World.

\section{Principles}

Our model is grounded in three principles: practicality, robustness, and minimalism. Johan Huizinga famously coined the phrase Homo Ludens to describe what he viewed as one of the fundamental properties of our species, play. Since Huizinga we have seen the possibilities for play expand rapidly, due in no small measure to technological advances. As play is intertwined more and more within everyday life, culture and technology, we have designed this model to serve as an descriptive schema that can accommodate the rapidly increasing variety of forms play assumes, driven by a knowledge economy that thrives on innovation and novelty, a culture that prizes spectacle and a neomaniacal consumer base.

\section{Practicality}

Our model is intended as a tool for both analysis and production. Whilst one can place the model over an existing game situation to articulate keys and relations between objects, one may also begin with a tabula rasa and plan a design through an ideational mapping of objects and relations. Indeed for instances of game production, we believe design and analysis should proceed simultaneously in a reciprocal dynamic, not dissimilar to the Agile mode of software development.

\section{Robustness}

Whilst more than a few models, noted earlier, have been proposed for the comprehension of games and play, all falter when confronted with certain mediums, modes of play, or arrangement of objects within the Game Event. Our model was conceived to provide explanatory power to any type of Game Event, from pervasive games to football matches to massively multiplayer online games (MMOGs); also to any type of object within the event, from human players to DualShock 4 controllers to Pac-Man power pellets, White-browed Scrub-wrens and Indiana Jones. All are counted as real if they perturb other objects within the Game Event: the more affect, the more real. 


\section{Minimalism}

Though we leverage much academic theory, we are primarily concerned with offering a user-centred design; that is to say, an accessible, comprehensible tool. Therefore we have taken liberties in adapting, reconfiguring or disregarding aspects of theory as we see fit to make the model internally sensible. We wish for our model to convey itself as straightforwardly as possible, bolstered by its theoretical foundations without simultaneously groaning underneath their weight. To this end, we have made a conscious choice to avoid dogmatic adherence to our theoretical inspirations; our model requires an epistemological nimbleness in its construction resonant with its intended breadth of application.

\section{OUR MODEL}

Following the above our model, as a general heuristic concept for play, is not tailored towards any specific medium, genre, or game system; it is an ideal structure meant to assist and guide empirical inquiry, not replace it. We also understand the analytical deployment of our model as correlating with the approach inspired by Alfred Schutz's work often referred to as ethnophenomenology. This idiographic approach acknowledges, and indeed emphasises, the filtering of experience through a subjective lens, seeking to find intersubjective commonalities that can be used to define generic features of the phenomenon, i.e. inductive reasoning; similarities with Goffman’s frame analysis are clear. 


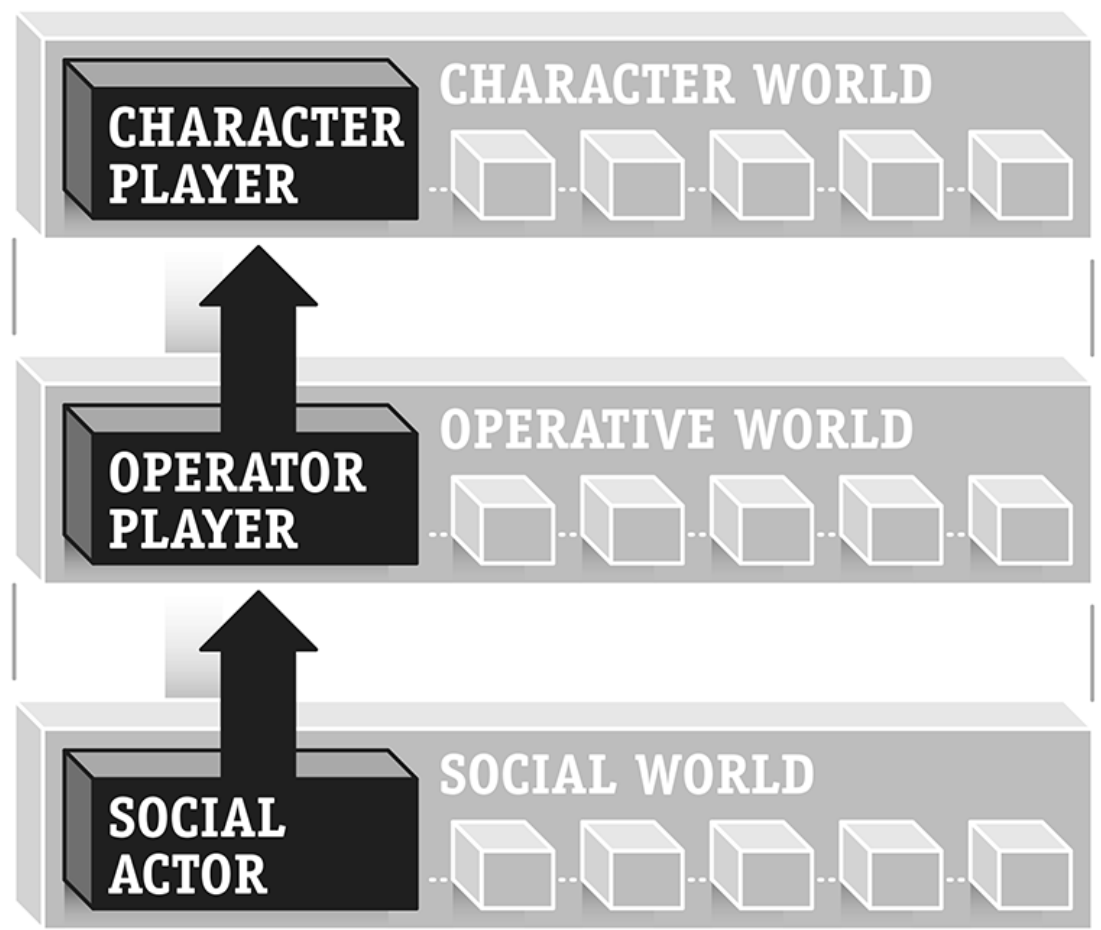

Figure 2: Mapping a human user's upkeying.

Therefore to provide consistency within our case studies (see section 4), we focus on the Game Event from the perspective of a single species of object: specifically we consider the human user's relationship to the Game Event, as Social Actor, Operator Player, and Character Player (see figure 2).

\section{3a. Three Levels: Social World/Operative World/Character World}

We follow Lakoff and Johnson's (2004) discussion of structural and orientational metaphor in offering a model whereby more effort is required to move upwards than downwards. For example, my 'everyday' experience of being Steven is much easier to maintain 
than a belief that I am Lara Croft. To borrow from Goffman, the 'Social Actor/Social World' is a primary frame, an untransformed scenario: in this world Steven exists but Steven-as-Lara does not; assault exists but boxing does not. Conversely, within the 'Character Player/Character World’ lamination,[1] Steven-as-Lara exists whilst Steven waits patiently in the zuhanden Social World; boxing is possible within the Operative and Character Worlds, but assault impossible: once assault occurs, the Game Event breaks and participants are downkeyed back to the Social World.

Goffman notes that games are focused encounters:

"[a] single visual and cognitive focus of attention; a mutual and preferential openness to verbal communication; a heightened mutual relevance of acts; an eye-to-eye ecological huddle that maximizes each participant's opportunity to perceive the other participants' monitoring of him. Given these communication arrangements, their presence tends to be acknowledged or ratified through expressive signs, and a "we rationale" is likely to emerge, that is, a sense of the single thing that we are doing together at the time. Ceremonies of entrance and departure are also likely to be employed, as are signs acknowledging the initiation and termination of the encounter or focused gathering as a unit.” (1972, pp.17-18)

Thus the Social Actor key is the most fundamental, and easiest to maintain within the frame of the Game Event. Whilst one must always exist within the lowest key, one may not always exist in the highest, 'Character Player/Character World'. To achieve entry into this key requires a particular collusion (Giddings 2009), a tremendous unified effort between the objects in the network, player included; as Ruggill and McAllister note, players must "work intensely hard to inhabit the different subjectivities required by each individual game" (2011, p.33).

This 'work' is the ongoing process of much negotiation: only when 
the majority of objects collude to move upwards together is there a chance of success. For example, it is very hard to upkey to Character Player within the board game of Chess as the minimalist board design and player pieces (traditionally black or white, mostly abstract shapes) make little effort to upkey the player; I exist on the level of Operator Player, as the game demands, and speaking as Character Player ("I am general of the white pieces!") could perhaps only be credible in jest. Goffman concludes:

"The world made up of the objects of our spontaneous involvement and the world carved out by the encounter's transformation rules can be congruent, one coinciding perfectly with the other... Where this kind of agreement exists... the participants will feel at ease or natural, in short, that the interaction will be euphoric for them.” (1972, p.38)

Thus it is much easier to upkey in a game where the entire network of objects colludes, indeed insists that the player move upwards in his or her relation to the Game Event. In this way digital games are perhaps the most articulate medium for upkeying to Character Player, considering the suite of tools available to hail the user-as-character, to quote Ruggill and McAllister once more, "computer games insist that players let loose their present subjectivity (e.g., mother, student, soldier, teacher) and mold themselves into one proffered by the game at hand" (2011, p.34). These insistences are evident in all kinds of feedback within digital games: from audio-visual design ("my avatar looks heroic") to narrative ("thanks Hero!”) to mechanics ("1000 points, winner!”) to haptic (strong vibrations indicating you are taking harm) and beyond. 


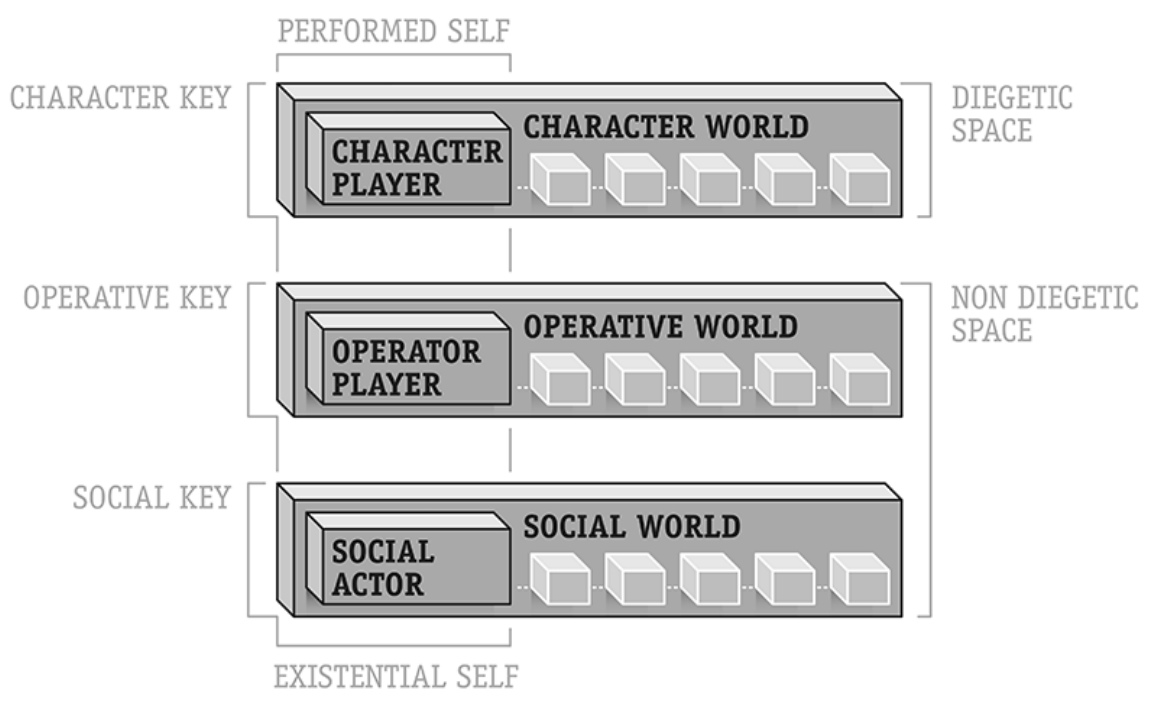

Figure 3: Our model articulated in relation to other theoretical constructs.

\section{CASE STUDIES}

In this section we offer a selection of demonstrative case studies focused upon the human user's relation to the Game Event and the various objects within. These are not to be understood as typical object relations for the medium or genre within which they sit. Instead they have been selected as particularly popular, novel or illuminating moments of object relations aimed to offer analytical light, on the one hand, and an example of the breadth of objects accessible to the designer, so often invisible, on the other.

\section{Football}

Referee Horacio Elizondo stands statuesque, a red card held accusingly in his right hand. The recipient, France's Zinedine Zidane, appears nonplussed as Elizondo points him towards the touchline. The tribal timbre of Berlin's Olympiastadion drops to a confused mesh of questioning voices.

It is the final of the 2006 football World Cup, and the world's best 
player, in his final professional match no less, has been sent off; downkeyed by Elizondo from Operator Player to Social Actor. Yet no one appears to know why. For viewers at home it becomes clear a matter of seconds later, as slow motion replays fill screens: Zidane had forcefully headbutted Italy’s Marco Materazzi in the chest.

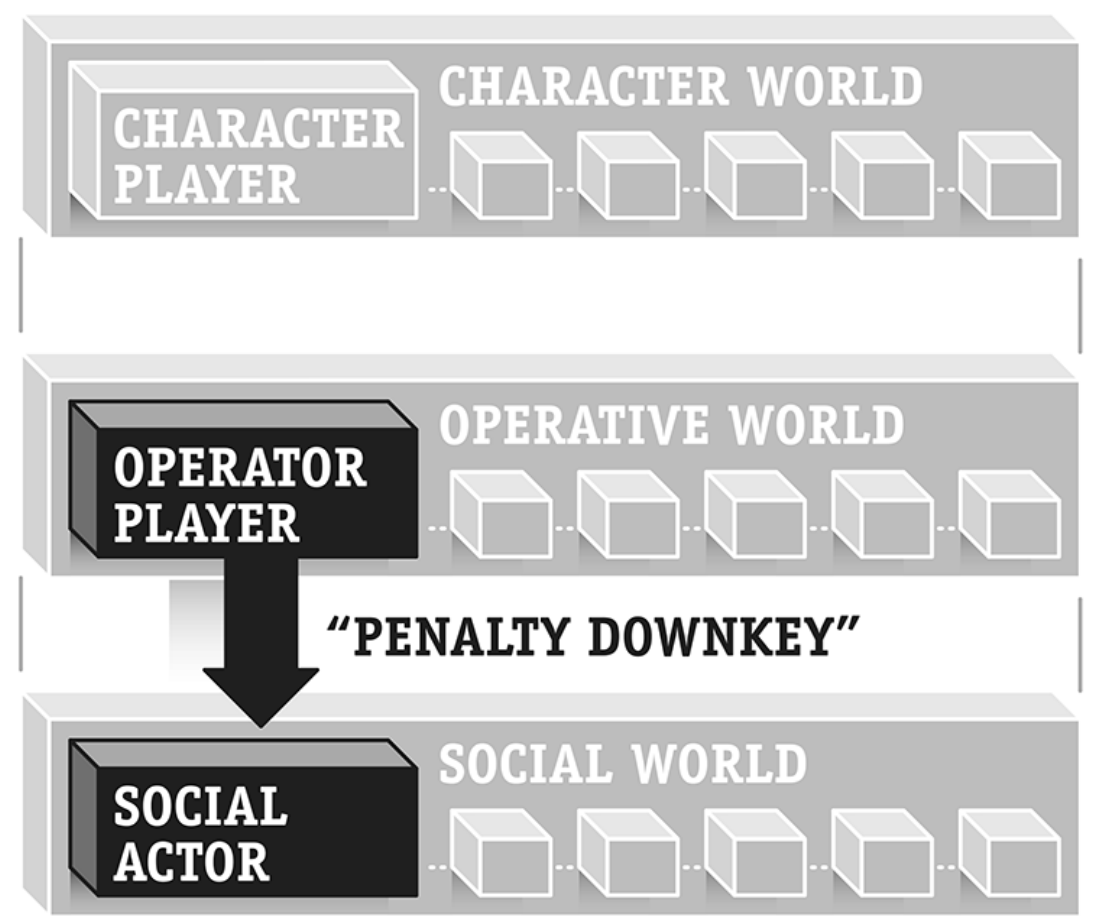

Figure 4: The most severe sanction in many Game Events is to downkey a user to Social Actor.

An excellent example of what Whannel terms 'vortextuality' (2010), the incident achieves a vortex effect, dominating the mediascape and drawing towards it an eclectic suite of high-profile commentators; at one point even the then-president of France, Jacque Chirac, is compelled to offer his public support to Zidane. 
The headbutt itself stands as a fascinating example of illegal object relations within a game: though it may relate to the ball, one's head must never intentionally engage with an opponent's chest in football, yet it is allowed in certain other contact sports (e.g. until UFC 15: Collision Course, headbutting was allowed within the Ultimate Fighting Championship).

It is interesting to note Zidane's reason for the headbutt: Materazzi had offered a very offensive description of his sister. Materazzi had upkeyed resources from the Social World, knowledge of Zidane's family, into the Operative World. Instead of speaking to Zidane as an Operator Player (footballer), he spoke to him as a Social Actor (a man with a sister), aware that one can never leave the social fully behind when playing a game. He is, in Huizinga's terms, a spoilsport; in modern videogame parlance, a griefer. For this method of griefing (there are many), one simply needs to upkey a knowledge of the target group's socio-cultural values, their habitus, to borrow from Bourdieu. Indeed, within the French-Algerian press Zidane's headbutt was articulated as a typically Algerian reaction to such an insult, in opposition to his French upbringing (Winterstein 2008). 


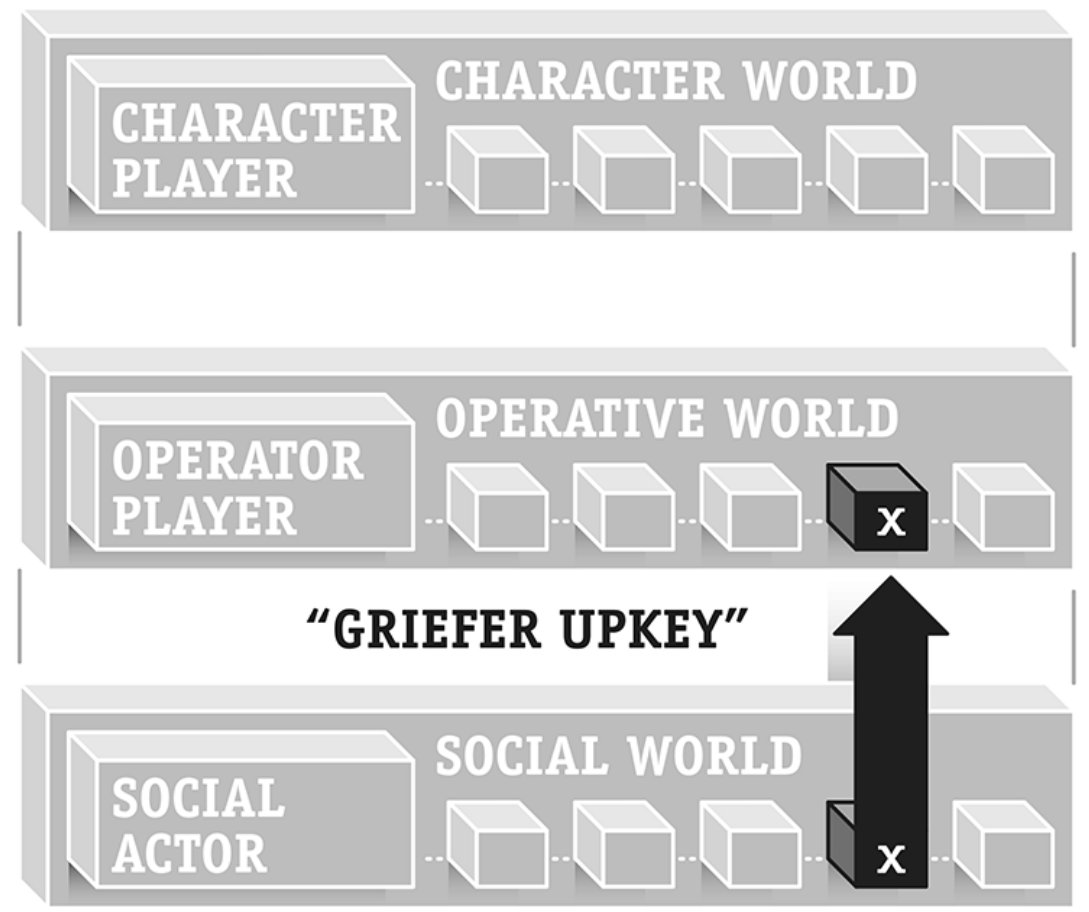

Figure 5: Griefing is an inappropriate upkey of Social World resources.

The practice of upkeying from the social to the Operative World (see figure 5) is, then, very common: in Massively Multiplayer Online Games (MMOGs), players upkey all kinds of external software programs into the Operative World to facilitate play; new player dynamics are invented simply through the upkeying of alcohol as a penalty object within many games, from Mario Kart (Nintendo 1992-present) to Darts. This leads us to note that upkeying is also at times a rather dangerous, sometimes disruptive movement. Asides from alcohol and knowledge of another player's Social World, as a broad example, one simply needs to upkey money into any game to witness a change in various object relations.

\section{Hideo Kojima}


“Blackout!” announces psychic villain Psycho Mantis; the user's television screen turns black with green text, 'HIDEO', glowing in the upper-right. This is a boss-battle taking place within Metal Gear Solid. Under the pretext of Psycho Mantis' psychic powers, all sorts of objects (the PlayStation 1 memory card, the DualShock controller's vibration motors, and the television) are upkeyed into the Game World. The encounter is an opaque acknowledgment of the often transparent network of objects that come together in generating the video game Black Box.

In this moment the television becomes an alien object, suddenly obtrusive, filling my intentionality. Similarly Metal Gear Solid's creator, Hideo Kojima, demands deference as the network's ultimate owner; this vorhanden strategy is indeed often labeled as 'breaking the fourth wall'. Yet this does not result in the sense of alienation, between myself and the Game World, that Bertolt Brecht would advocate: my immersion in the fiction remains.

In fact, the opposite occurs: through conspicuous manipulation of the network of objects within the Game Event, the world of Metal Gear Solid becomes more encompassing, more persuasive. It is a hallmark of Kojima's work that he plays with this keying between worlds: in the above example the television, previously existing on the level of the Operative World, is upkeyed by Psycho Mantis into the Game World. During this famous boss-battle Psycho Mantis will also upkey the DualShock controller, the memory card, and even the controller ports (the user will have to switch from controller port 1 to port 2 so that Psycho Mantis cannot 'read the mind' of the user and dodge all attacks). As shorthand, we call this movement of objects into the Game World the 'Kojima Upkey’ (see figure 6). 


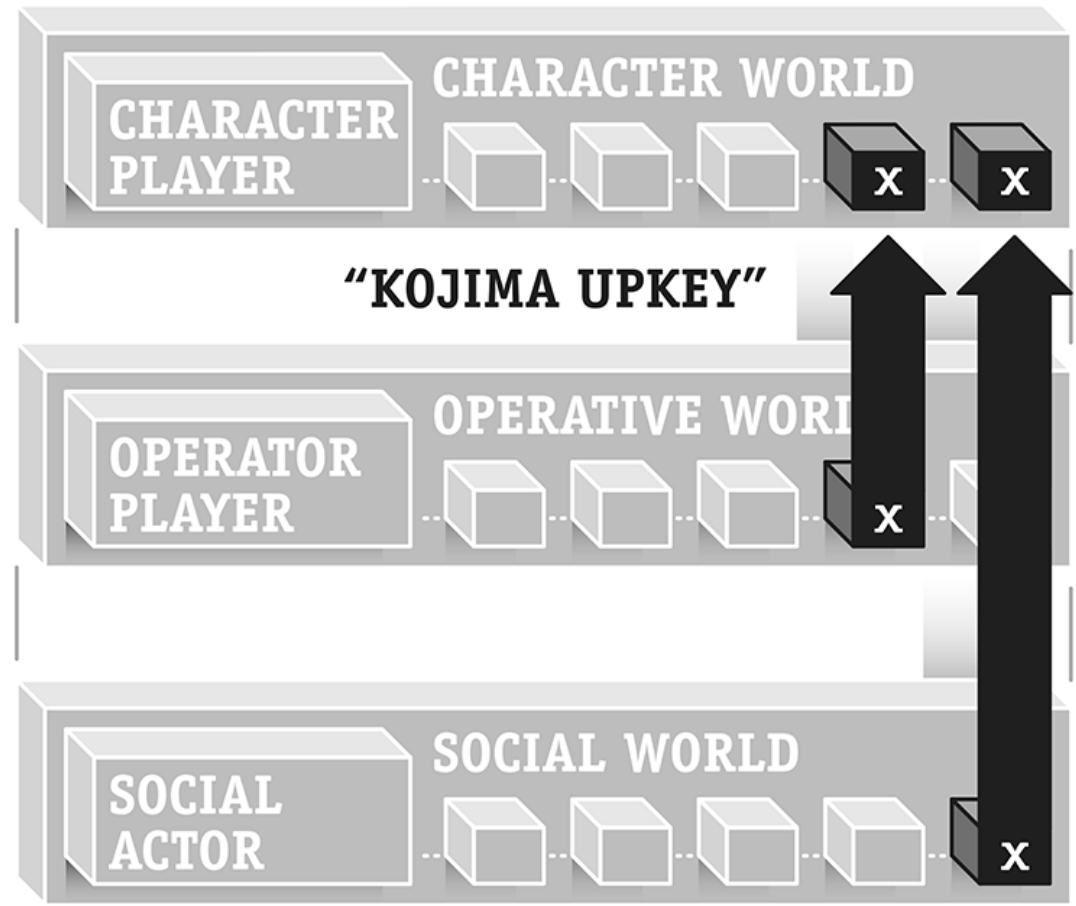

Figure 6: A typical movement of objects within Game Events designed by Hideo Kojima.

This signature rekeying is evident across Kojima's oeuvre: one of Kojima's earliest games, 1988's Snatcher (Konami), heavily relies on upkeying science-fiction films of the time, most obviously Ridley Scott's Blade Runner (1982), whilst Kojima also planned to distribute the game on heat sensitive floppy disks that generated the smell of blood and revealed messages under certain temperatures (Gilbert 2012). In Boktai: The Sun Is In Your Hand [2] (Konami Computer Entertainment Japan 2003), the sun is upkeyed from Social to Character World via a photometric light sensor embedded within the Game Boy Advance's cartridge, as UV rays charge the weapon of the protagonist (a vampire hunter). 


\section{Sometimes You Die}

"What makes you accept this as a game?

The category in the App Store?

That you want to be entertained?

How low must the level of fun be...

not to call it a game?

Is it the fact that it follows rules?

That you go from left to right?

What is it that you call 'game'?” (Stollenmayer 2014)

I have just launched the 2014 iOS game Sometimes You Die (Stollenmayer 2014) on my iPhone5S, when developer Philipp Stollenmayer begins my interrogation. His questions appear as a collection of disconnected words amid a seemingly random pastiche of dimmed text, glowing on the back wall of this room-by-room platforming puzzle game. The words are read aloud by a digitally altered voice. A ransom note and a telephone call from a Hollywood kidnapper fused into the passage of play.

Stollenmayer's agenda is clear here: he will not allow my experience of his game to go unchallenged. My engrossment will be subject to his relentless critical examination, and on reflection, my own. Here then, the voice of Game Designer is present, tangible within the Game World, willfully engaging the Operator Player in an interlocution that dissects the experience itself, the medium upon which it is delivered and the device upon which it is played. Stollenmayer's dissonant form of address forces a pattern of rapid oscillation as my intentionality is, moment to moment, redirected between all three levels of the game event.

As I progress, his interventions become ever more surreal. 'You rely on a promise that I do not change the rules ... You expect obedience ... I never gave a promise. I could make you pay for every level.' An in-app purchase pop-up appears on screen, recognisably dressed in 
the livery of Apple’s iOS7. 'Do you want to pay \$9,999 to unlock this level?' My input options are 'Yes' and 'Yes'. With great trepidation and knowing full well that my banker will block the payment, I tap the lesser of the two affirmative options and the text changes. 'No you don't. Use this pop-up to reach the exit'. So prompted, I realise that the pop-up has been made concrete within the diegesis, transformed into a platform I can use to reach a previously inaccessible exit. This again, is what we term the 'Kojima Upkey'. An object from the Social World upkeyed into the Operative World, its previous utility discarded as it assumes a new role in the Game Event.

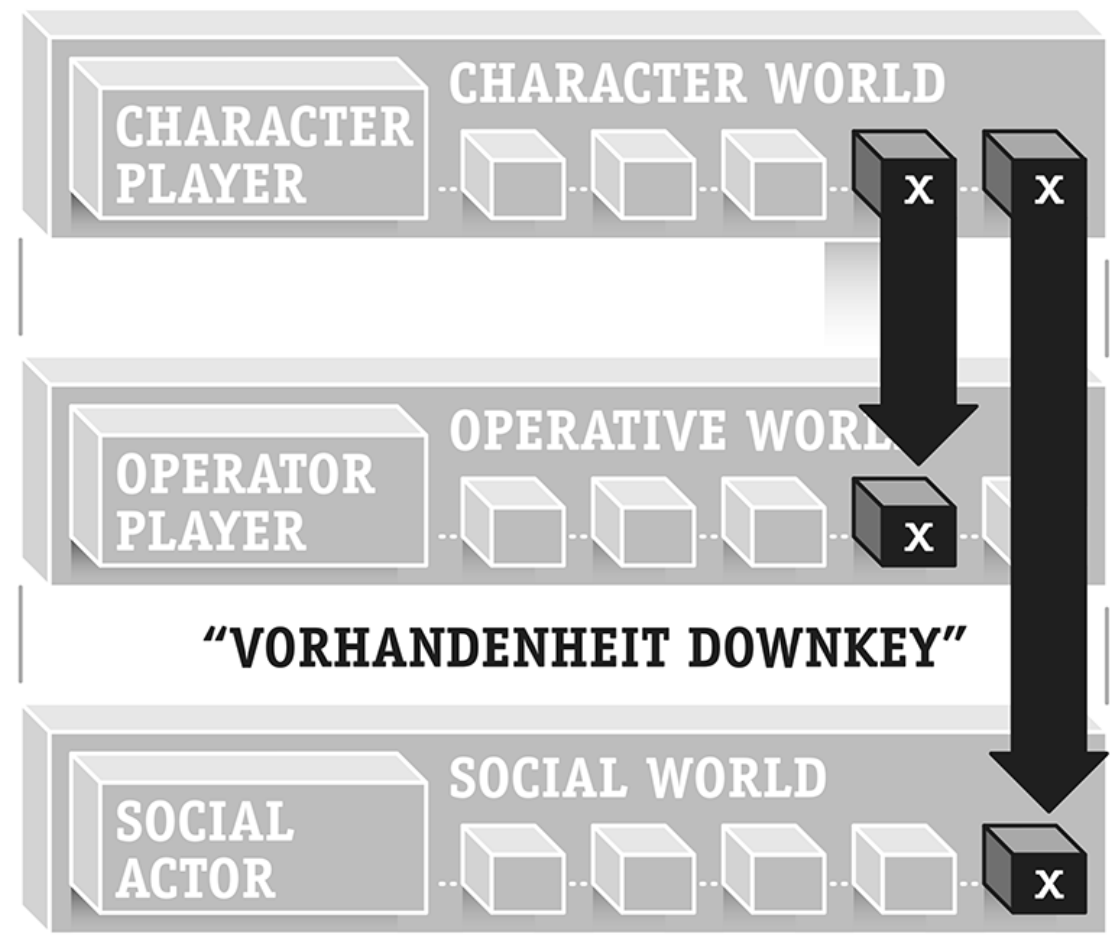

Figure 7: The Vorhandenheit Downkey

'I could change the rules'. As this ominous statement is made, my 
operative control of the black square beyond the flawless lens of the screen has been suddenly and appallingly rewired. Pushing left now causes my avatar to jump, right $=$ left and jump = right. With this latest assault the iPhone5S, zuhanden until moments ago, fills my consciousness. Like my keyboard earlier in the article, it has become vorhanden and I stare at it witlessly, my hard earned mastery of the virtual controls entirely lost, my proprioceptive, muscle memory rendered useless and my engrossment severed. We term this kind of moment the 'Vorhandeneit Downkey' (see figure 7). The iPhone5S has become present-at-hand and I must renegotiate my relationship with it and in turn Stollenmayer's infernal creation. 'How much more of this will you take', he seems to be asking. 'No more' I decide, and close the app, blinking at the commuters in the train carriage I have been riding all the while. I have downkeyed intentionally to the Social World and resume my role as Social Actor, pocketing my phone and shifting my weight carefully lest I disturb the passenger next to me, engrossed as she is in Candy Crush Saga (King 2012).

\section{I'm with stupid...}

"Peter! It's Deadpool. What the hell is High Moon doing to my game?!? Look, use the money I transferred to your account and patch this shit! Now!” (High Moon Studios 2013)

My avatar, Deadpool is quite literally speaking on the phone with Peter Della Penna, President of High Moon, the game development studio responsible for Deadpool (High Moon Studios 2013). We have arrived at a door, beyond which the game level is clearly incomplete. Placeholder textures are wallpapered across primitive geometry in corridors patrolled by T-posed, as yet unanimated enemies. Clearly, the eponymous character I'm attempting to pilot is not impressed. Della Penna complies, the door closes and after Deadpool taps his foot for a few seconds a loading bar fills, signaling the arrival of new content. The door opens once more on a now completed scene. As 
with Sometimes You Die, the voice and role of the Game Developer has been upkeyed from the Social World to the Operative and Character Worlds.

It is not the first time the two have spoken in my play through. In fact the game begins with the premise that it is being made at the protagonist's insistence (blackmail, death threats), that Deadpool has script approval, can negotiate budget and even prematurely determine when the game ends should he so choose: 'Ok, that's it, roll credits, we're done here'. This will be no great surprise to fans of the Marvel character, known for his 'fourth-wall awareness'. In his comics, Deadpool knows he is a comic-book superhero and in his game, he knows he's the star of a game. This awareness affords him unmediated access to all of the objects in the Black Box and he resignifies them with delirious frequency. An avatar with an agenda, gleefully transgressing every convention of genre and creative constraint of console hardware, in what is otherwise a by-thenumbers, third-person action adventure.

Here too is an entity that refuses to allow the Operator Player to upkey to Character Player for long, by continuously renegotiating the terms of the focused encounter to suit his own motivations. Deadpool wants to satisfy his own adolescent power fantasies, and the hapless player (like the game's developer) is simply another object deployed to that end. In this sense, Deadpool is diametrically opposed to the compliant, often silent, empty vessels players of digital games so often pilot in pursuit the very same gratifications.

The character is also explicitly aware of the player's role in all this and takes pleasure in pointing out his dissatisfaction with the relationship: 'Hopefully, when we wake up, you'll be gone'. It is at these moments, when our avatar speaks to us at the level of the Operative and sometimes Social World, that we can identify a fourth wall break consistent with the theatrical origins of the term; he heckles the audience (see figure 8). 


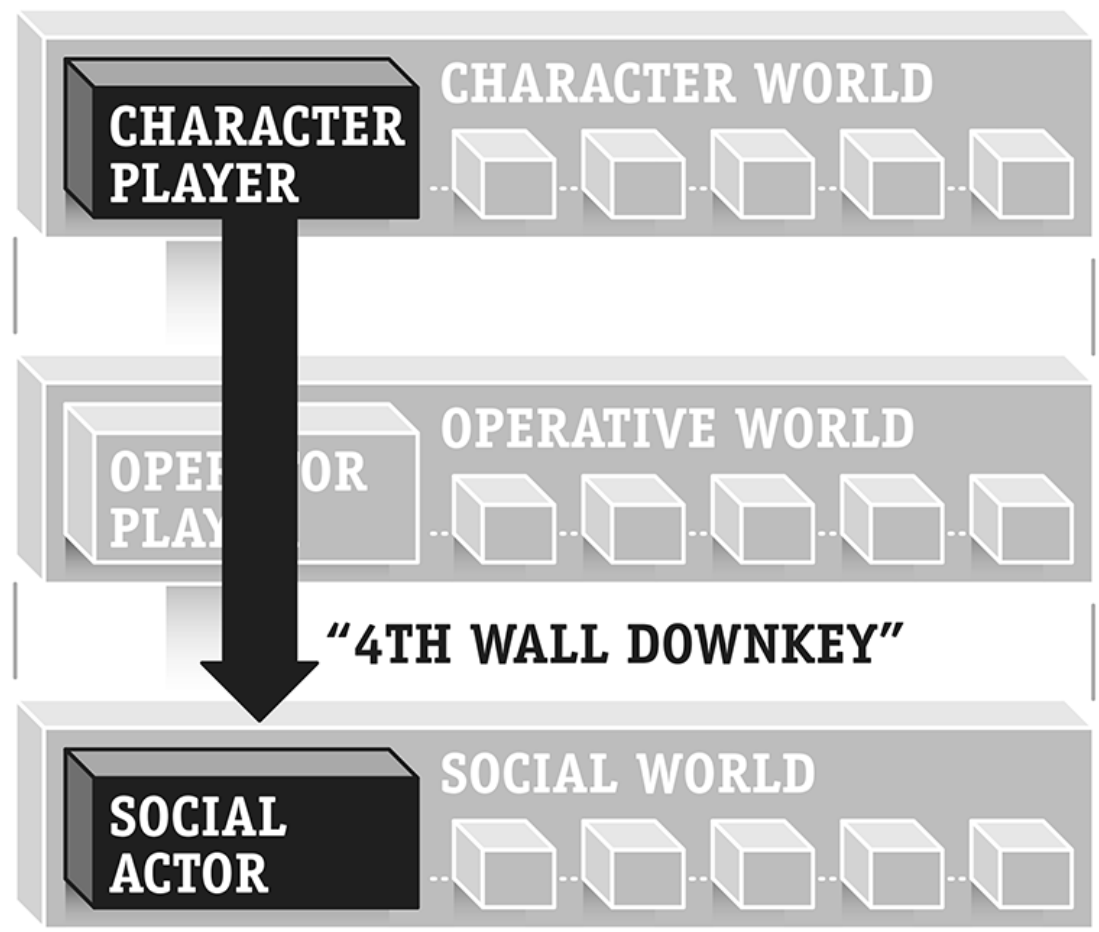

Figure 8: Deadpool frequently kicks the user out of the Game Event.

Later in our adventure, Deadpool takes off alone, exhorting the player to try and keep up. The umbilici that tether character to camera and DualShock input to character action have been suddenly severed. The real-time camera in the game is now all I'm able to pilot. It has been upkeyed from somewhere deep in the Black Box and I push forward, attempting to catch up to my wayward charge, like an embedded camera operator in a war-zone. Downkeyed once more, this time to Operator Spectator, I realise there's no colluding with Deadpool. I'm merely a passenger on his quixotic ride.

\section{CONCLUSION: OBJECT LUDENS}

To summarise, we must recognise that Huizinga's Homo Ludens is, 
in its very conception, a misnomer: man of play cannot exist without a whole host of allied objects colluding. Sometimes these objects are predisposed to afford play, generally through designer intention, other times they are momentarily leashed, keyed into the Game Event accidentally, unwillingly or illegally, as when head meets chest in football, rain meets grass in tennis, or angry bird meets promiscuous sensor device. Games are Black Boxes: the accumulation of a vast number of objects that comes together, oftentimes incognito, to produce a Game Event.

The aim of our model, then, is to provide illumination. The box is broad, deep and frequently unpredictable, therefore our model is robust and minimal: we must not offer an a priori prescription of objects, or relationships within any Game Event. Much like Latour's Actor-Network Theory, our model only comes into being through practical application, as illustrated in section 4 . This is a distinction we maintain for analysis, however for design we advocate the model as both an exercise for pure ideation, in the planning phase, and tool for diagnosis, in the development phase.

That said, a few key factors underlying our model should be reiterated. Firstly, in borrowing terms from other fields and disciplines to describe the Game Event, we should be careful we do not dull the analyst's scalpel for the sake of convenience. Metalepsis, paratext, non-diegetic, and fourth walls, to name a few, may all have their place in specific discussions, but we recommend one deploy such terms in a critical, reflective manner.

Secondly, the agency of the non-human must be acknowledged: as Apperley \& Jayemanne (2012), Deterding (2013), Giddings (2009) and Keogh (2014) have lately concluded, amongst others, the Game Event cannot emerge solely through human toil. Chairs, broadband infrastructures, carbon fibre, Skype, Indiana Jones, steroids and contrast ratio may all have their moment to perturb the Game Event, and therefore all must be mappable. Though our model is still in its early stages, and will no doubt undergo further iteration, we hope that 
the Social, Operative and Character World offer enough robustness and flexibility to accommodate most applications.

Lastly, binary distinctions, for example between the real and the virtual, the game and the everyday, are perhaps more damaging than beneficial in coming to an aetiology of the Game Event. Whilst we must be attentive to differences between the material and the ideal, we must not accord deference to the material over the ideal prior to analysis: the object plane begins flattened, compressed, and only takes shape through observation, once the Black Box is opened. Similarly, one should recognise the different object relations, and therefore meanings, that come into being in varying contexts, and crucially, at various instants. Though the diagrams provided within this article illustrate particular object relations, they are merely still photographs capturing fleeting moments: synchronic rather than diachronic. Our model must sometimes run at 60 frames-per-second to capture the complexity and fluidity of the event as it unfolds across time.

\section{ACKNOWLEDGMENTS}

We dedicate this article to the late Dr Peter Bayliss, whose groundbreaking work in applying phenomenology to games had a decisive influence upon the authors' thinking. Rest in peace, Pete. We would also like to acknowledge the generous and thoughtful feedback provided by Sebastian Deterding, Jonas Linderoth, the Learning Games Initiative and the Swinburne Game Research Group to early sketches of this article. We also wish to thank our three anonymous reviewers for their extremely helpful critiques.

\section{ENDNOTES}

[1] For the sake of minimalism, we here do away with the term 'lamination', opting to persevere with key.

[2] Our thanks to Darshanna Jayemanne, who pointed us towards this game. 


\section{BIBLIOGRAPHY}

Apperley, T. H., and D. Jayemanne. "Game Studies’ Material Turn.” In Westminster Papers in Communication and Culture vol. 9, no. 1 (2012): 5-25.

Ash, J. "Technologies of Captivation Videogames and the Attunement of Affect Body.” In Body \& Society vol. 1, no. 19 (2013): 27-51.

Bogost, I. "Materialisms: The Stuff of Things Is Many.” In Ian Bogost - Videogame Theory, Criticism, Design. Web (2010). http://www.bogost.com/blog/materialisms.shtml.

Bryant, L. The Democracy of Objects. London, UK: Open Humanities Press, 2011.

Clark, A. Natural-Born Cyborgs: Minds, Technologies, and the Future of Human Intelligence. Oxford: Oxford University Press, 2003.

Deterding, S. "Modes of Play: A Frame Analytic Account of Video Game Play.” PhD, Universitat Hamburg, 2013.

Dourish, P. Where the Action Is: The Foundations of Embodied Interaction. Cambridge, MA: MIT Press, 2004.

EA Canada. FIFA 14. [Xbox One]. Electronic Arts, 2013. Played February 2014.

Fine, G. A. Shared Fantasy: Role Playing Games as Social Worlds. London: The University of Chicago Press, 1983.

Gadamer, H. Philosophical Hermeneutics. Translated by David E. Linge. Berkeley: University of California Press, 1976.

Galloway, A. R. Gaming: Essays on Algorithmic Culture. London: University of Minnesota Press, 2006. 
Giddings, S. "Events and Collusions: A Glossary for the Microethnography of Videogame Play.” In Games and Culture: A Journal of Interactive Media vol. 4, no. 2 (2009): 144-157.

Gilbert, B. "Hideo Kojima Recalls Snatcher's Heat-Activated Disk (what?).” Joystiq. 16 March, 2012, http://www.joystiq.com/2012/03/ 16/hideo-kojima-recalls-snatchers-heat-activated-disk-what/

Goffman, E. Encounters: Two Studies in the Sociology of Interaction. Harmondsworth: Penguin University Books, 1972.

Goffman, E. The Presentation of Self in Everyday Life. New York: The Overlook Press, 1973.

Goffman, E. Frame Analysis: An Essay on the Organization of Experience. Boston, MA: Northeastern University Press, 1986.

Harman, G. The Quadruple Object. Winchester: Zero Books, 2011.

Heidegger, M. Being and Time. New York, NY: Harper Perennial Modern Thought, 2008.

High Moon Studios. Deadpool. [PS 3]. Activision 2013. Played May 2014.

Hunicke, R., M. LeBlanc, and R. Zubek. "MDA: A Formal Approach to Game Design and Game Research.” 2004. http://www.cs.northwestern.edu/ hunicke/pubs/MDA.pdf.

Keogh, B. "Across Worlds and Bodies: Criticism in the Age of Video Games.” In Journal of Games Criticism vol. 1, no. 1 (2014), http:/gamescriticism.org/articles/keogh-1-1/.

King. Candy Crush Saga. [Apple iPhone 5S]. King 2012. Played May 2014.

Konami. Snatcher. [PC]. Konami 1992. Played January 2008.

Konami Computer Entertainment Japan/Kojima Productions. Metal 
Gear Solid series. [PS 1-4]. Konami 1998-present. Played March 2014.

Konami Computer Entertainment Japan. Boktai: The Sun Is In Your Hand. [Game Boy Advance]. Konami 2003. Played February 2014.

Lakoff, G., and M. Johnson. Metaphors We Live By. Chicago, IL: University of Chicago Press, 2003.

Latour, B. Science in Action: How to Follow Scientists and Engineers through Society. Boston, MA: Harvard University Press, 1988.

Latour, B. We Have Never Been Modern. Cambridge, MA: Harvard University Press, 1993.

Latour, B. Reassembling the Social: An Introduction to ActorNetwork Theory. Oxford: Oxford University Press, 2005.

Linderoth, J. "The Effort of Being in a Fictional World: Upkeying and Laminated Frames in MMORPGs.” In Symbolic Interaction vol. 35, no. 4 (2012): 474-492.

Norman, Donald A. The Design of Everyday Things. New York, NY: Basic Books, 2002.

Ricoeur, P. Hermeneutics and the Human Sciences, edited by John P. Thompson. Cambridge: Cambridge University Press, 1981.

Ruggill, J. E., and K. S. McAllister. Gaming Matters: Art, Science, Magic, and the Computer Game Medium. Tuscaloosa: University of Alabama Press, 2011.

Schell, J. The Art of Game Design: A Book of Lenses. New York: Morgan Kaufmann Publishers, 2010.

Schutz, A. "On Multiple Realities." In Collected Papers: The Problem of Social Reality, edited by M. Natanson, 207-259. Nijhoff: The Hague, [1945] 1962. 
Scott, R. Blade Runner. Warner Bros 1982.

Stollenmayer, P. Sometimes You Die. [Apple iPhone 5S]. 2014. Played May 2014.

Sucker Punch Productions. Infamous Second Son. [PlayStation 4]. Sony Computer Entertainment 2014. Played June 2014.

Whannel, G. "News, Celebrity, and Vortextuality: A Study of the Media Coverage of the Michael Jackson Verdict.” In Cultural Politics vol. 6, no. 1 (2010): 65-84.

Winterstein, D. "The Other Algeria: Zidane, World Cup Soccer, Globalization, and the Media.” In Impumelelo: The Interdisciplinary Electronic Journal of African Sports vol. 3 (2008). https://www.ohio.edu/sportsafrica/journal/Volume3/ theotheralgeria_winterstein.htm 